\title{
Recuperação de pastagem degradada pelo consórcio de milho, Urochloa brizantha cv. Marandu e guandu
}

\author{
Alex da Silva ${ }^{1}$, Fenelon Lourenço de Sousa Santos², Vitor Corrêa de Mattos Barretto ${ }^{3}$, \\ Roberto José de Freitas ${ }^{1}$, João Kluthcouski ${ }^{4}$ \\ ${ }^{1}$ Universidade Estadual de Goiás, Campus Ipameri, Ipameri, Goiás, Brasil. E-mail: alexsosgo@ hotmail.com, rjf05@uol.com.br \\ ${ }^{2}$ Centro Universitário de Goiás - Uni-Anhanguera, Goiânia, Goiás, Brasil. E-mail: lourenco_dm@ hotmail.com \\ ${ }^{3}$ Universidade Estadual Paulista, Campus de Dracena, Dracena, São Paulo, Brasil. E-mail: barrettovitor@ yahoo.com.br \\ ${ }^{4}$ Empresa Brasileira de Pesquisa Agropecuária - Embrapa Cerrados, Brasília, Distrito Federal, Brasil. E-mail: \\ kluthcouski@embrapa.br
}

Recebido: 19/12/2016; Aceito: 08/12/2017

\section{RESUMO}

Objetivou-se com esse trabalho avaliar a viabilidade da recuperação de pastagens degradadas através do banco de sementes presente na área, com a utilização do sistema de consórcio de milho com pastagem com feijão guandu. $\mathrm{O}$ delineamento experimental foi em blocos ao acaso, em esquema fatorial $2 \times 3$ composto pela utilização ou não do guandu e 3 densidades de semeadura da forrageira (banco de semente $-0 \mathrm{~kg} \mathrm{ha}^{-1} ; 2 \mathrm{~kg} \mathrm{ha}^{-1} \mathrm{e} 4 \mathrm{~kg} \mathrm{ha}^{-1}$ ), com 4 repetições. Foram avaliados: o número de espigas por planta, altura de inserção da primeira espiga, altura de plantas, número de fileiras de grãos por espiga, número de grãos por fileira, peso de cem grãos, produtividade do milho, rendimento de biomassa verde do milho, rendimento de biomassa seca do milho, biomassa seca da Urochloa brizantha cv. Marandu, biomassa verde e seca do feijão guandu. Os resultados demonstram que as sementes presentes no banco de semente das áreas degradadas são viáveis para recuperar a pastagem por meio do consórcio. A utilização do guandu aumenta a produção de forragem até a densidade de semeadura de $2 \mathrm{~kg} \mathrm{ha}^{-1} \mathrm{da}$ forrageira. $\mathrm{O}$ uso do consórcio milho, braquiária e guandu não causa prejuízos à cultura do milho em relação aos seus componentes de produção.

Palavras-chave: banco de semente, Integração Lavoura Pecuária, Cajanus cajan.

\section{Recovery of degraded pasture by the maize intercropping with Urochloa brizantha cv. Marandu and pigeon pea}

\begin{abstract}
The objective of this work was to evaluate the feasibility of the recovery of degraded pastures with the seed bank present in the area, using the maize + pasture + pigeon pea integrated system. The experimental design was a randomized complete block design in a $2 \times 3$ factorial scheme composed of the use of pigeon pea and three forage seeding densities (seed bank, $0 \mathrm{~kg} \mathrm{ha}^{-1}, 2 \mathrm{~kg} \mathrm{ha}^{-1}$ and $4 \mathrm{~kg} \mathrm{ha}^{-1}$ ), with 4 replicates. The number of spikes per plant, height of insertion of the first spike, plant height, number of rows per spike, number of grains per row, weight of one hundred grains, maize grain yield, maize fresh mass yield, dry mass yield of maize, Urochloa brizantha cv. Marandu, and pigeon pea. The results demonstrate that the seeds present in the seed bank of the degraded areas are viable to recover the pasture through the consortium. The use of pigeon pea increases forage production up to the seeding density of $2 \mathrm{~kg} \mathrm{ha}^{-1}$ of forage. The use of the maize, brachiaria and pigeon pea integrated does not cause damage to the maize crop in relation to its production components.
\end{abstract}

Key words: seed bank, Integration Crop Livestock, Cajanus cajan. 


\section{Introdução}

Detentor do maior rebanho comercial do mundo, o Brasil é o maior exportador de carne bovina e sexto maior produtor de leite. Nesse contexto, a bovinocultura, um dos setores mais representativos do agronegócio e da economia nacional, apesar do destaque no cenário mundial apresenta baixos índices de produtividade, devido ao baixo investimento em biotecnologias pelos produtores e a baixa capacidade de suporte das pastagens, em torno de 1,3 $\mathrm{UA} \mathrm{ha}^{-1}$ (DIASFILHO, 2011).

Com uma área de 172,3 milhões de hectares ocupadas com pastagens naturais e plantadas (IBGE, 2007) a produção bovina do país se dá basicamente nesse ambiente. No entanto, estima-se que desse total, cerca de 50 a $70 \%$ apresentam algum grau de degradação (DIAS-FILHO, 2011), justificando a baixa capacidade de suporte das pastagens do país. Notadamente, esse cenário de degradação deve-se a exploração por décadas da fertilidade natural dos solos em áreas desmatadas para a implantação de forrageiras com alto potencial produtivo e consequentemente de alta exigência nutricional (OLIVEIRA; CORSI, 2005).

Além da exaustão dos nutrientes do solo, o superpastejo dos animais é provavelmente o principal responsável pela degradação das áreas de pastagens, uma vez que a redução da altura do dossel da forrageira favorece a entrada de raios solares, propiciando a emergência de plantas daninhas com sementes fotoblásticas positivas, reduzindo o potencial produtivo das forrageiras da área devido à competição.

No intuito de recuperar e renovar as pastagens, a integração lavoura-pecuária mostra-se como uma solução viável pois a cultura comercial cobre os custos da renovação, além do melhor aproveitamento dos insumos utilizados, principalmente fertilizantes e corretivos de solo. Recentemente foi lançado o Sistema Santa Brígida (OLIVEIRA et al., 2010) que utiliza o consórcio milho, forrageira e leguminosa. Geralmente, como leguminosa o guandu anão é utilizado com objetivo de melhorar a qualidade nutricional das forragens produzidas, fazer aporte de nitrogênio no sistema através da fixação biológica além da diversificação da microbiocenose do solo.

Os sistemas de consórcio são altamente eficientes considerando a possibilidade de serem implantados em áreas com solos corrigidos ou parcialmente corrigidos (COBUCCI et al., 2007). Desta forma, o aumento da capacidade de suporte evita a conversão de áreas de florestas naturais em área para exploração animal, porém, o investimento inicial em renovação/recuperação de pastagens é alto (OLIVEIRA; CORSI, 2005). Vilela et al. (2011) apontam como vantagem desse sistema a possibilidade de a produção agrícola arcar, no primeiro ano, com parte dos custos da implantação do sistema.
As principais forrageiras cultivadas no Brasil são facilmente estabelecidas via sementes (CASTRO et al., 2008). No entanto, para germinação das sementes é necessário a disponibilidade de água, luz, temperatura e profundidade de semeadura (CARVALHO; CHRISTOFFOLETI, 2007). Na falta das condições para germinar, as sementes entram em estado de dormência (CASTRO; VIEIRA, 2001). Essas sementes viáveis que ficam presentes no solo recebem o nome de banco de sementes (SIMPSON et al., 1989).

Investigando a produção de sementes em cultivares de Urochloa brizantha Quadros et al. (2012) relatam produtividades de 154,7 e $188,2 \mathrm{~kg} \mathrm{ha}^{-1}$ de sementes puras viáveis das cultivares Marandú e Xaraés, respectivamente; quantidade muito maior que a necessária para o estabelecimento inicial de pastagens.

Considerando que o uso da ILP promove uma melhoria na fertilidade dos solos e que mesmo em pastagens degradadas ocorre a produção de sementes ainda que não possam germinar devido à falta de condições favoráveis, permanecendo no banco de sementes, objetivou-se com esse trabalho investigar a viabilidade da recuperação de pastagem degradadas com as sementes presentes no banco de semente da área utilizando ILP com milho solteiro e consorciado com guandu-anão.

\section{Material e Métodos}

O experimento foi desenvolvido na Fazenda Santa Brígida, em Ipameri, GO (1743'19'’S, 4809'36'”W e altitude aproximada de $815 \mathrm{~m}$ ), em área de pastagem de Urochloa brizantha cv. Marandu degradada. O clima local é classificado como Cwa, tropical de altitude, segundo Köppen. O solo utilizado foi classificado como Latossolo Vermelho distrófico típico, com textura argilosa (EMBRAPA, 2006).

Foram coletadas amostras na camada de 0-20 cm para a caracterização físico-química do solo, tendo apresentado os seguintes resultados: $\mathrm{pH}\left(\mathrm{H}_{2} \mathrm{O}\right)=5,2 ; \mathrm{P}$ $\left.(\mathrm{mg} \mathrm{dm})^{-3}\right)=10,8 ; \mathrm{K}^{+}\left(\mathrm{cmol}_{\mathrm{c}} \mathrm{dm}^{-3}\right)=153 ; \mathrm{Ca}^{2+}\left(\mathrm{cmol}_{\mathrm{c}}\right.$ $\left.\mathrm{dm}^{-3}\right)=2,8 ; \mathrm{Mg}^{2+}\left(\mathrm{cmol}_{\mathrm{c}} \mathrm{dm}^{-3}\right)=1,4 ; \mathrm{H}^{+}+\mathrm{Al}^{3+}\left(\mathrm{cmol}_{\mathrm{c}}\right.$ $\left.\left.\mathrm{dm}^{-3}\right)=3,5 ; \mathrm{V}(\%)=56,74 ; \mathrm{Zn}(\mathrm{mg} \mathrm{dm})^{-3}\right)=10,7$; matéria orgânica $\left(\mathrm{g} \mathrm{dm}^{-3}\right)=33,0$; carbono $\left(\mathrm{g} \mathrm{dm}^{-3}\right)=$ 19,14; areia $\left(\mathrm{g} \mathrm{kg}^{-1}\right)=470$; silte $\left(\mathrm{g} \mathrm{kg}^{-1}\right)=110$ e argila $\left(\mathrm{g} \mathrm{kg}^{-1}\right)=420$.

$\mathrm{O}$ delineamento experimental utilizado foi em blocos casualizados, em esquema fatorial $2 \times 3$, com quatro repetições. Os tratamentos constituíram-se do cultivo de milho com e sem guandu consorciado, além de 3 densidades de semeadura da forrageira no consórcio (somente o banco de sementes da área $-0 \mathrm{~kg}$ $\mathrm{ha}^{-1} ; 2 \mathrm{~kg} \mathrm{ha}^{-1}$ e $4 \mathrm{~kg} \mathrm{ha}^{-1}$ ). Cada parcela foi constituída por seis linhas de $10,0 \mathrm{~m}$ de comprimento ( 5 metros para avaliação da produção de grãos e $5 \mathrm{~m}$ para 
avaliação da produção de biomassa), espaçadas em 0,60 m. Como área útil da parcela, foram consideradas as duas linhas centrais, sendo que 1,0 $\mathrm{m}$ da extremidade de cada linha de plantas e as duas linhas externas constituíram-se na bordadura.

A pastagem degradada foi previamente dessecada com a aplicação de glifosato $\left(1.800 \mathrm{~g} \mathrm{ha}^{-1}\right.$ do ingrediente ativo), com volume de calda de $120 \mathrm{~L} \mathrm{ha}^{-1}$, em pré-semeadura. O híbrido de milho utilizado foi o Pioneer P3862H, semeado em SPD no dia 27 de dezembro de 2014, por meio de semeadora-adubadora com caixas de sementes espaçadas de $0,30 \mathrm{~m}$ uma da outra, sendo utilizada uma caixa entre as linhas de milho para a semente do feijão guandu anão cv. Super N. A adubação de semeadura foi constituída por $450 \mathrm{~kg} \mathrm{ha}^{-1}$ do formulado NPK 08-20-15; já na adubação de cobertura, foram utilizados $350 \mathrm{~kg} \mathrm{ha}^{-1}$ do formulado 36-00-12. A adubação descrita anteriormente e o controle de pragas, doenças e plantas daninhas foram realizados de acordo com as necessidades da cultura.

A semeadura da braquiária foi feita simultaneamente à semeadura do milho e do guandu, utilizando-se a terceira caixa da semeadora, específica para sementes de forrageira em sistema de consórcio. Nesse sistema de plantio, as sementes são lançadas sobre o solo e incorporadas pelo revolvimento causado pela própria semeadora. Aos 90 DAS foram cortadas as plantas presentes na metade da área útil da parcela $(5,0 \mathrm{~m})$ a 40 $\mathrm{cm}$ de altura, sendo posteriormente trituradas para determinar o rendimento da biomassa verde, levando o material para a estufa de circulação forçada de ar para determinação da biomassa seca.

A colheita do milho foi realizada manualmente, aos 115 dias após a semeadura (DAS), coletando-se todas as espigas na área útil de cada parcela $(5,0 \mathrm{~m})$. A seguir, realizou-se a trilha mecânica e determinação da umidade das amostras, e correção para 13\%. Nesta ocasião, determinou-se, também, o número de espigas por planta, a altura de inserção da primeira espiga, altura das plantas, número de fileiras de grãos por espiga, número de grãos por fileira, peso de cem grãos e produtividade.

A massa da forragem de $U$. brizantha cv. Marandu e do Cajanus cajan cv. Super N, foram determinadas com o método do quadrado inventário de $1,0 \mathrm{~m}^{2}$, consistindo da média de quatro amostragens aleatórias por parcela, com todo o material coletado sendo pré-seco em estufa de circulação forçada de ar $\left(65{ }^{\circ} \mathrm{C}\right)$. Em seguida, realizou-se a pesagem e o cálculo da biomassa da forragem $\left(\mathrm{kg} \mathrm{ha}{ }^{-1}\right.$ de matéria seca). Os cortes foram realizados na altura de $0,20 \mathrm{~m}$ em relação à superfície do solo, logo após a colheita do milho.

Os dados foram submetidos à análise de variância, teste de Scoot-Knot a 5\% e quando necessário, a análise de regressão, para o fator densidade de semeadura da forrageira.

\section{Resultados e Discussão}

O uso de leguminosas, assim como as diferentes densidades de semeadura da forrageira não influenciaram as características morfológicas e agronômicas da cultura do milho (Tabela 1). Os resultados mostram que o consórcio com a Urochloa brizantha cv. Marandu tampouco com o feijão guandu propiciaram efeitos nas características de altura das plantas de milho (Figura 1A) e na altura da inserção da primeira espiga (Figura 1B). Da mesma forma, a semeadura adicional da forrageira não interferiu nessas características.

Experimentos conduzidos por Ceccon et al. (2014), investigando o comportamento do milho consorciado com braquiárias relatam a redução na altura das plantas de milho quando consorciado com braquiária, contradizendo os resultados obtidos nesse trabalho.

Tabela 1. Análise de variância das características morfológicas e agronômicas da cultura do milho cultivado sob diferentes densidades de semeadura de Urochloa brizantha cv. Marandu e na presença de feijão guandu, em Ipameri- GO, 2015.

\begin{tabular}{|c|c|c|c|c|c|c|c|c|}
\hline \multicolumn{9}{|c|}{ Quadrados médios } \\
\hline $\begin{array}{l}\text { Fonte de } \\
\text { variação }\end{array}$ & GL & NEP & AIE & $\mathrm{AP}$ & NFG & NGF & P100 & PROD \\
\hline Bloco & 3 & $0,013^{\text {ns }}$ & $0,0009^{\text {ns }}$ & $0,0063^{\mathrm{ns}}$ & $0,677^{\mathrm{ns}}$ & $0,1647^{\mathrm{ns}}$ & $7,82^{\mathrm{ns}}$ & $2840,72^{\mathrm{ns}}$ \\
\hline Capim(C) & 2 & $0,0002^{\mathrm{ns}}$ & $0,0036^{\mathrm{ns}}$ & $0,0045^{\mathrm{ns}}$ & $0,406^{\mathrm{ns}}$ & $0,0210^{\mathrm{ns}}$ & $0,40^{\mathrm{ns}}$ & $44059,54^{\mathrm{ns}}$ \\
\hline Guandú & 1 & $0,00001^{\mathrm{ns}}$ & $0,0192^{\mathrm{ns}}$ & $0,0012^{\mathrm{ns}}$ & $0,844^{\mathrm{ns}}$ & $0,0216^{\mathrm{ns}}$ & $1,28^{\mathrm{ns}}$ & $42580,79^{\mathrm{ns}}$ \\
\hline $\mathrm{C} \times \mathrm{G}$ & 2 & $0,0001^{\mathrm{ns}}$ & $0,0009^{\mathrm{ns}}$ & $0,0002^{\mathrm{ns}}$ & $0,594^{\mathrm{ns}}$ & $0,5937^{\mathrm{ns}}$ & $2,39^{\mathrm{ns}}$ & $1893,85^{\mathrm{ns}}$ \\
\hline Resíduo & 15 & 0,0016 & 0,0062 & 0,0053 & 0,235 & 0,3043 & 8,01 & 35859,34 \\
\hline C.V. (\%) & & 3,70 & 5,45 & 2,74 & 4,74 & 6,53 & 7,37 & 8,02 \\
\hline
\end{tabular}

$\mathrm{NEP}=\mathrm{n}^{\circ}$ de espigas por planta; $\mathrm{AIE}=$ altura de inserção da primeira espiga; $\mathrm{AP}=$ Altura de plantas; $\mathrm{NFG}=\mathrm{n}^{\circ}$ de fileiras de grãos por espiga; $\mathrm{NGF}=$ número de grãos por fileira; P100 = Peso de cem grãos; PROD = Produtividade; ns = não significativo ao teste de Scott-Knott a 5\% de probabilidade. 


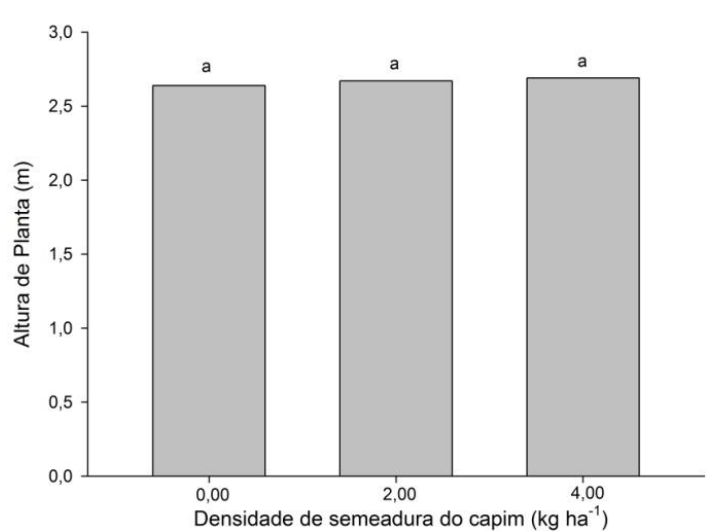

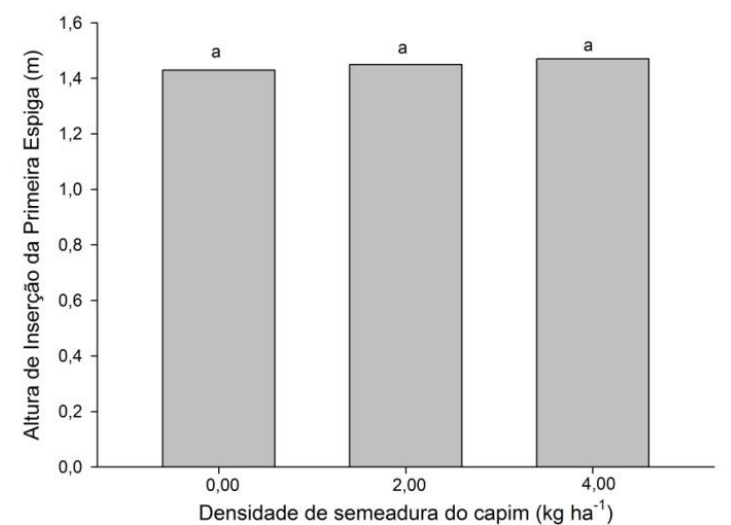

Figura 1. Altura de plantas de milho (A) e da inserção da primeira espiga (B) em função da densidade de semeadura de $U$. brizantha cv. Marandu.

Com relação à altura de inserção da espiga todos os tratamentos apresentaram valores acima de $1,4 \mathrm{~m}$, no entanto, não houve interação significativa entre o consórcio da forrageira e da leguminosa (Figura 1B). Segundo Cortez et al. (2009), esta característica está relacionada diretamente com a altura das plantas e com genótipo utilizado. Marchão et al. (2005) preconizam que para a adoção de culturas consorciadas com o milho, a altura de inserção da espiga deve ser de no mínimo $1,0 \mathrm{~m}$, possibilitando a colheita mecanizada sem danos às culturas intercalares (COSTA; SILVA, 2008), devido à maior altura da plataforma de corte, reduzindo a possibilidade de embuchamento da máquina (BRAMBILLA et al., 2009).

A presença do feijão guandu no consórcio não afetou o número de espigas por planta. Do mesmo modo, a densidade de semeadura da forrageira não interferiu nessa característica (Figura 2). Segundo Freitas et al. (2013), no consórcio de milho com forrageiras, essa característica pode ser influenciada pelas competições intra e interespecíficas por fotoassimilados, fato que pode reduzir o índice de prolificidade devido ao aumento da esterilidade feminina na cultura.

Não foi observada interação significativa entre a utilização da leguminosa no consórcio com relação ao número de fileiras de grãos de milho, assim como as densidades de semeadura da braquiária também não influenciaram essa característica (Figura 3A). Estes resultados corroboram com os obtidos por Maia et al. (2015), que ao avaliarem $U$. brizantha não encontraram variação em relação ao número de fileiras de grãos. Segundo Marchão et al. (2005) esse comportamento provavelmente se justifica pelo fato da planta de milho definir seu potencial produtivo nos estágios iniciais, ocasião em que as culturas consorciadas ainda não causam prejuízos ao cereal. Esta característica tem forte controle genético sofrendo poucas influências do meio (FREITAS et al., 2013).

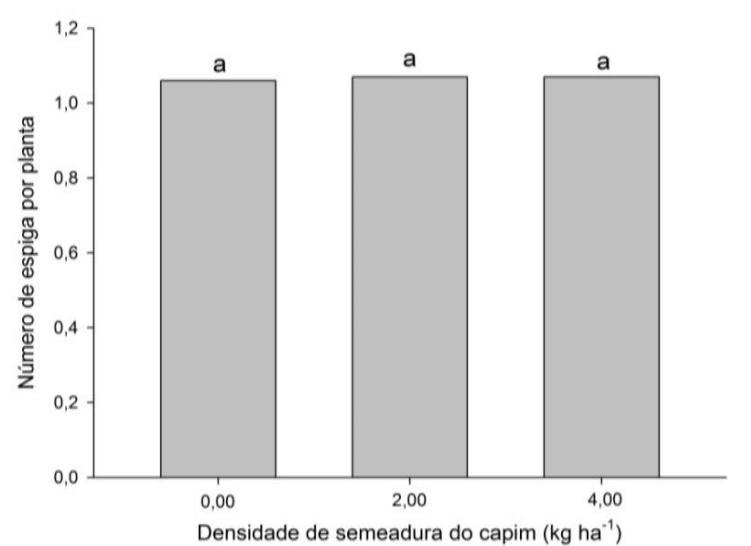

Figura 2. Número de espigas por planta de milho em função da densidade da semeadura de $U$. brizantha cv. Marandu.

Para o número de grãos por fileira, a presença da forrageira não influenciou nesta característica (Figura 3B). As espécies utilizadas no consórcio com o milho não competiram com o milho, permitindo que esse produzisse a quantidade adequada de fotoassimilados para a produção de grãos nas fileiras das espigas.

A presença da braquiária assim como o feijão guandu não influenciou o peso de cem grãos do milho (Figura 4A). Este resultado demonstra que não ocorreu competição entre as espécies utilizadas. Brambilla et al. (2009) afirmam que uma das características do milho híbrido é produzir grãos maiores quando cultivados sem competição com outras plantas.

No tocante à produtividade de grãos de milho, os sistemas avaliados não apresentaram diferenças significativas, com rendimento médio de aproximadamente $9.400 \mathrm{~kg} \mathrm{ha}^{-1}$ (Figura 4B); uma produtividade satisfatória, uma vez que a média nacional se encontra em pouco mais de $5.000 \mathrm{~kg} \mathrm{ha}^{-1}$ (CONAB, 2016). Este valor bem superior à média nacional, provavelmente deve-se ao nível tecnológico empregado durante a condução do experimento, ao híbrido utilizado, de elevado teto produtivo e ao fato de não ter ocorrido restrição hídrica para a cultura. 
A
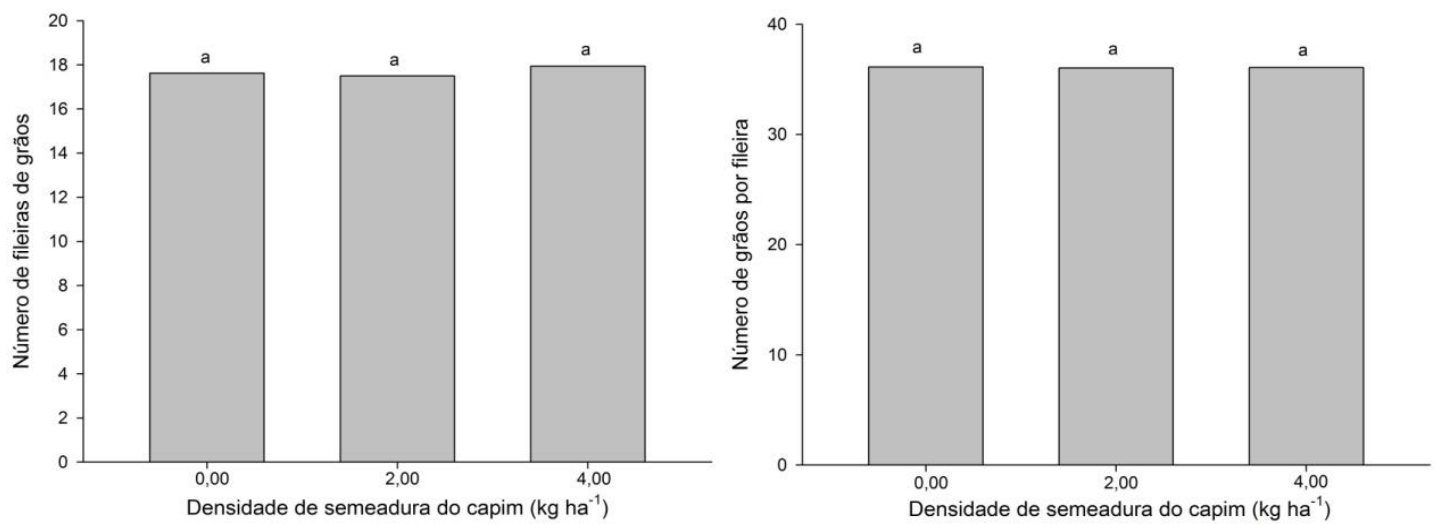

Figura 3. Número de fileiras de grãos (A) e número de grãos por fileira (B) em função da densidade da semeadura de $U$. brizantha cv. Marandu.

A

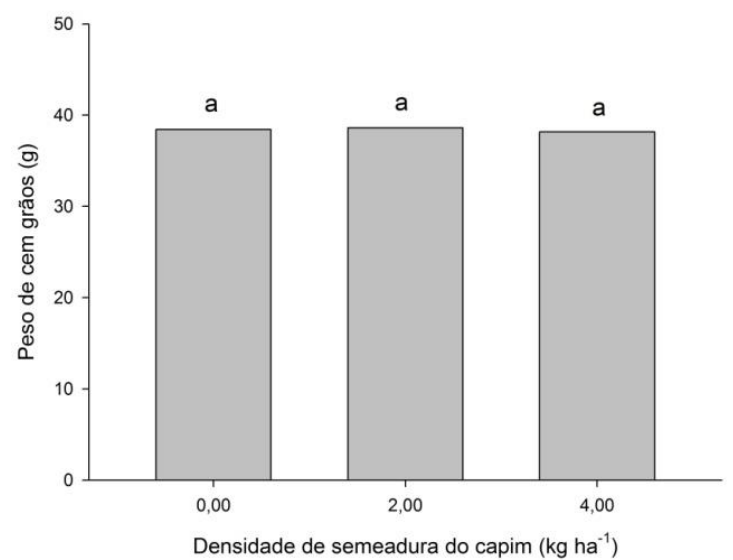

B

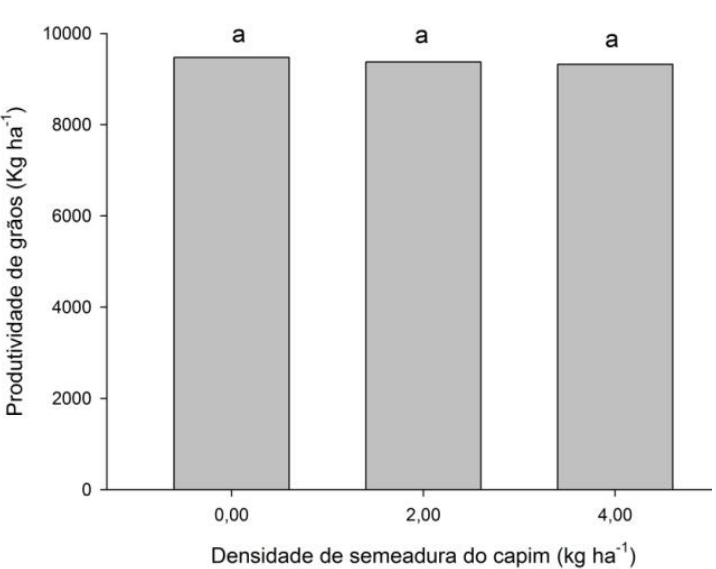

Figura 4. Peso de cem grãos de milho (A) e produtividade de grãos (B) em função da densidade da semeadura de $U$. brizantha cv. Marandu.

Os resultados obtidos condizem com os relatados por Heinrichs et al. (2005), que ao avaliarem espécies leguminosas intercaladas com a cultura do milho não observaram redução de produtividade na cultura. Com relação à presença forrageira no consórcio, os resultados corroboram com os relatados por Freitas et al. (2013), que não observaram redução da produtividade do cereal pela utilização da braquiária no sistema de integração.

A presença da braquiária no sistema, assim como o feijão guandu não apresentaram interação significativa com relação à produção de biomassa verde e seca do milho, no entanto, houve interação significativa para a utilização do guandu no consórcio em relação ao acúmulo de matéria seca da braquiária (Tabela 2). O milho apresentou rendimento de matéria verde acima de $50 \mathrm{Mg} \mathrm{ha}^{-1}$, independente da densidade de semeadura da braquiária utilizada (Figura 5A). Assim como na produção de grãos, os tratamentos não diferiram entre si, demonstrando a viabilidade desse tipo de consórcio tanto para produtores que visam a produção de grãos quanto para os pecuaristas que visam a produção de silagem, possibilitando uma diversificação na produção
(PIRES et al., 2009) e melhorando a qualidade da silagem produzida (LEONEL et al., 2009).

A produção de biomassa seca na cultura do milho comportou-se de forma similar, não apresentando diferenças entre as densidades de forragem utilizada e nenhuma interação com a presença da leguminosa (Figura 5B). Desta forma, a adoção desse tipo de consórcio (milho+braquiária+guandu) mostra-se viável, uma vez que não há perdas na produtividade do milho, independente da finalidade do cultivo (grãos ou silagem), além disso a presença da leguminosa pode melhorar as características bromatológicas tanto do material ensilado como da pastagem remanescente. Este resultado não condiz com os relatados por Brambilla et al. (2009) que ao estudarem o comportamento da cultura do milho consorciado com $U$. ruziziensis relatam uma redução do acúmulo de biomassa seca do cereal quando consorciado com a braquiária. No entanto, os autores ponderam que a redução de produtividade em sistemas consorciados é influenciada por um conjunto de fatores, como população adotada, ocorrência de plantas daninhas, condições climáticas, entre outros fatores. 
Tabela 2. Análise de variância da produção de biomassa da cultura do milho e da Urochloa brizantha cv. Marandu consorciada com guandu, em Ipameri-GO.

\begin{tabular}{lcccc}
\hline Fonte de variação & \multicolumn{4}{c}{ Quadrados médios } \\
\hline & GL & BIOMV & BIOMS & MSBRAQ \\
\cline { 2 - 5 } Bloco & 3 & $3953360,13^{\text {ns }}$ & $417544,88^{\text {ns }}$ & $347129,03^{\text {ns }}$ \\
Capim(C) & 2 & $18161293,49^{\text {ns }}$ & $1760586,86^{\text {ns }}$ & $8590733,89^{* *}$ \\
Guandú (G) & 1 & $16299626,67^{\text {ns }}$ & $2148621,02^{\text {ns }}$ & $1404,99^{\text {ns }}$ \\
Cx G & 2 & $3281499,16^{\text {ns }}$ & $296797,65^{\text {ns }}$ & $3259424,70^{*}$ \\
Resíduo & 15 & 7759446,43 & 1059471,87 & 632700,13 \\
\hline C.V. (\%) & & 6,30 & 5,75 & 7,94 \\
\hline
\end{tabular}

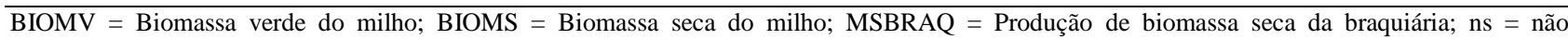
significativo ao teste de Scott-Knott a 5\% de probabilidade.

A

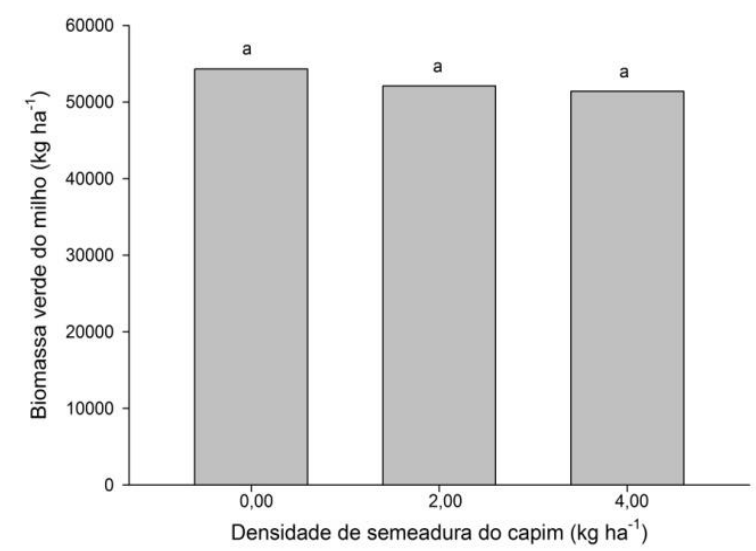

B

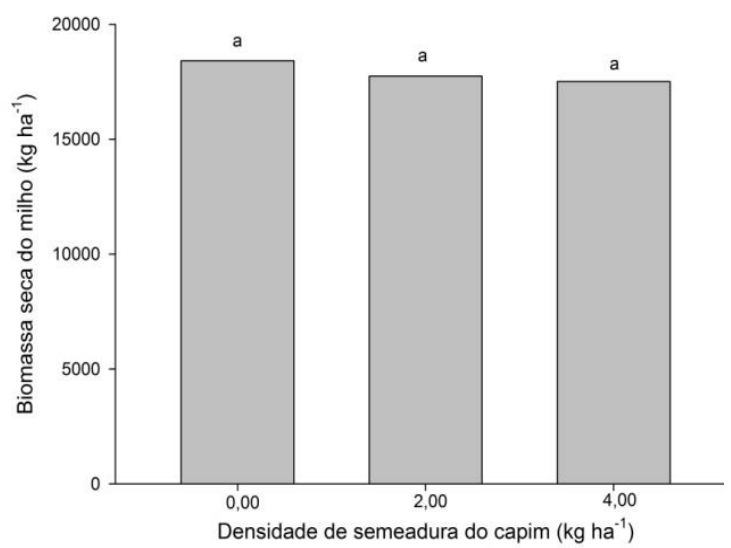

Figura 5. Produção de biomassa verde (A) e seca (B) das plantas de milho em função da densidade da semeadura de $U$. brizantha cv. Marandu.

A produção de biomassa da braquiária apresentou interação entre as densidades de semeadura e a utilização do guandu, apresentando um comportamento linear em relação às taxas de semeadura adotadas, esse comportamento era previsível, uma vez que a maior densidade de semeadura promoveria a maior emergência de plantas na área.

Nas parcelas que não tiveram a semeadura da forrageira, utilizando-se apenas o banco de sementes existente na área $\left(0 \mathrm{~kg} \mathrm{ha}^{-1}\right)$ o acúmulo de biomassa da forrageira foi superior ao das parcelas em que não se empregou a leguminosa. Esse comportamento foi mais proeminente nas parcelas em que se empregou $2 \mathrm{~kg} \mathrm{ha}^{-1}$ da $U$. brizantha cv. Marandu, verificando-se que o guandu promoveu o aumento da produção de biomassa de $12 \%$ em relação às parcelas onde havia somente milho e braquiária. Tal fato se deve ao aporte de nitrogênio promovido pelo guandu, beneficiando o crescimento da forrageira (Figura 6).

Quando se empregou $4 \mathrm{~kg} \mathrm{ha}^{-1}$ de sementes de braquiária, a presença da leguminosa reduziu a produtividade da forrageira. $\mathrm{O}$ aumento da competição intraespecífica, decorrente da maior população da forrageira, aliado à presença das plantas de maior porte no consórcio reduzem a disponibilidade de radiação solar além de estabelecer um microclima na região baixeira com temperaturas mais amenas, influenciando a regulação estomática da braquiária por ser uma espécie de ciclo metabólico $\mathrm{C} 4$. Os resultados obtidos corroboram com os relatados na literatura em trabalhos que investigaram o comportamento de forrageiras consorciadas com guandu demonstrando uma redução de altura e consequente acúmulo de biomassa promovido pela presença da leguminosa em consórcio com capim Piatã (DEMINICIS, 2009) e Tifton 85 (DEMINICIS, 2009; SANTOS et al., 2006).

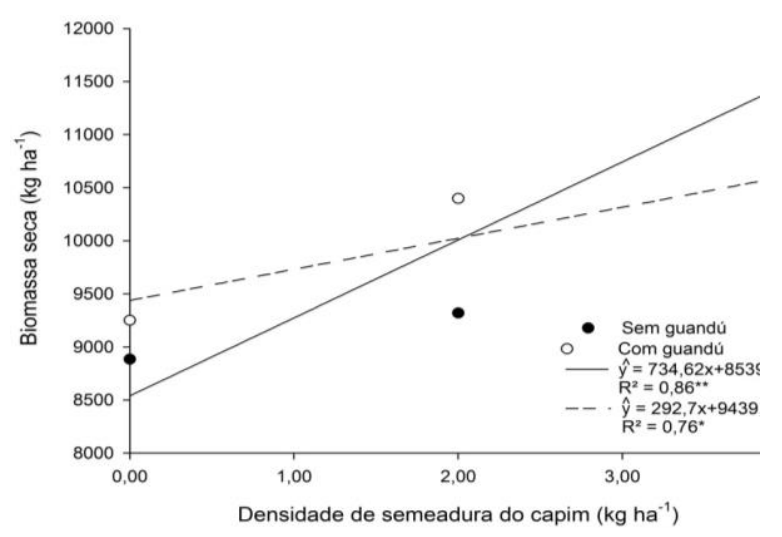

Figura 6. Produção de biomassa seca de $U$. brizantha cv. Marandu em função da densidade de semeadura. 
De modo geral, as produtividades de biomassa obtidas na forrageira neste trabalho, evidenciam a possibilidade da utilização dos sistemas consorciados com leguminosas na recuperação de pastagens degradadas, aproveitando o próprio banco de semente da área para o reestabelecimento. Embora a presença da leguminosa possa promover um menor acúmulo de biomassa da forrageira quando em altas densidades, a utilização da mesma tem papel fundamental dentro do sistema, sendo responsável pelo aumento dos teores de proteína bruta da forragem obtida (NERES et al., 2012), problema que pode ser contornado pela redução da densidade de plantio da forrageira - até a taxa de $2,0 \mathrm{~kg}$ $\mathrm{ha}^{-1}$ (Figura 6), como evidenciado no presente trabalho.

As densidades de semeadura do capim avaliadas não interferiram na produção de biomassa verde e seca do feijão guandu (Tabela3). As produtividades médias de biomassa da leguminosa foram de aproximadamente 27 e 5,2 $\mathrm{Mg} \mathrm{ha}^{-1}$ para biomassa verde (Figura 7A) e biomassa seca (Figura 7B) respectivamente.

Esses resultados estão de acordo com os citados por Moreira et al., (2003) que encontrou produtividades de feijão guandu variando entre 18,67 e $21,38 \mathrm{Mg} \mathrm{ha}^{-1}$. Com relação à produtividade de matéria seca, Suzuki e Alves (2006) obtiveram produtividades de $6,46 \mathrm{Mg} \mathrm{ha}^{-1}$.
Possivelmente essas variações relatadas se devem às condições experimentais, além dos materiais avaliados. É importante destacar que mesmo em consorciação a leguminosa não foi influenciada pela forrageira, apresentando rendimentos médios próximos aos relatados na literatura para o cultivo solteiro da espécie.

No presente trabalho o rendimento da leguminosa demonstra sua viabilidade para utilização no sistema de consórcio com o milho e braquiária, uma vez que não compromete a produtividade do cereal e ainda produz grande quantidade de biomassa aumentando a disponibilidade de alimento dos animais após a colheita.

Tabela 3. Análise de variância da produção de matéria verde e seca do feijão guandu consorciado com milho e braquiária em diferentes densidades de semeadura da forrageira, em IpameriGO.

\begin{tabular}{|c|c|c|c|}
\hline Fonte de & & Quadrados mé & \\
\hline & GL & MVG & MSG \\
\hline Bloco & 3 & $43586790,62^{\mathrm{ns}}$ & $1678707,95^{\mathrm{ns}}$ \\
\hline Capim & 2 & $8999280,01^{\mathrm{ns}}$ & $355883,83^{\mathrm{ns}}$ \\
\hline Resíduo & 6 & 53176301,19 & 1967575,35 \\
\hline C.V. (\%) & & 26,88 & 26,72 \\
\hline
\end{tabular}

A

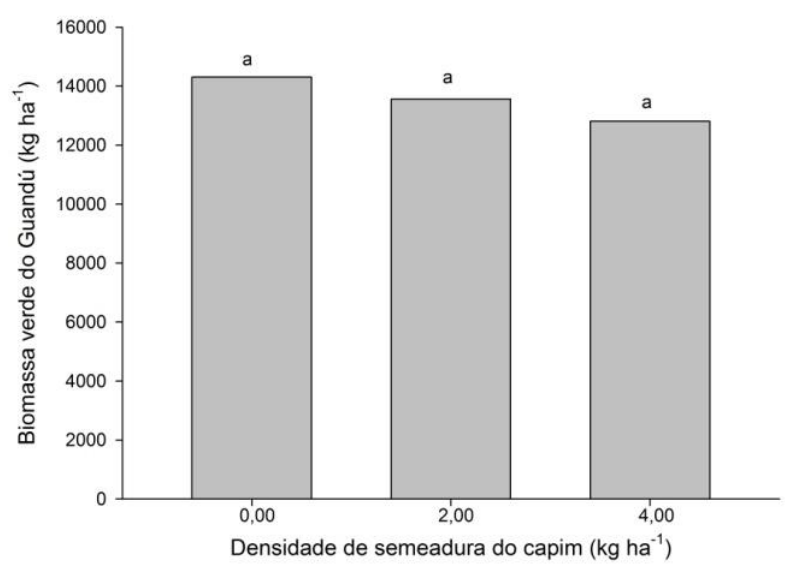

B

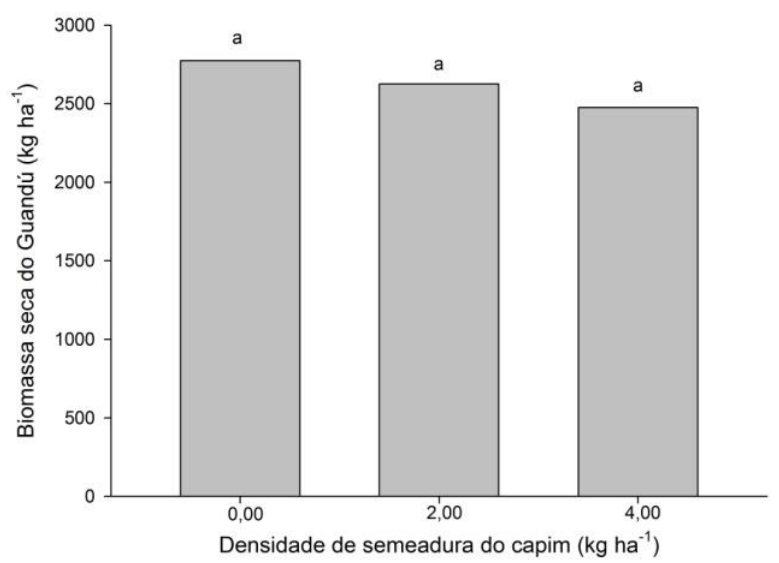

Figura 7. Produção de biomassa verde (A) e seca (B) do guandu em função da densidade da semeadura de U. brizantha cv. Marandu.

\section{Conclusões}

Em áreas de pastagem degradada, o uso do banco de sementes pode ser viável para a recuperação da pastagem com a utilização da integração lavourapecuária.

O uso do feijão guandu aumenta a produtividade da forrageira em consórcio com milho até a densidade de semeadura de $2 \mathrm{~kg} \mathrm{ha}^{-1}$ da forrageira.

O consórcio milho, braquiária e feijão guandu não causa prejuízos à cultura do milho em relação aos seus componentes de produção.

\section{Referências Bibliográficas}

BRAMBILlA, J. A.; LANGE, A.; BUCHELT, A. C.; MASSAROTO, J. A. Produtividade de milho safrinha no sistema de integração lavoura-pecuária, na região de Sorriso, Mato Grosso. Revista Brasileira de Milho e Sorgo, Sete Lagoas-MG, v. 8, n. 3, p. 263-274, 2009.

CARVALHO, S. J. P.; CHRISTOFFOLETI, P. J. Influência da luz e da temperatura na germinação de cinco espécies de plantas daninhas do gênero Amaranthus. Bragantia, Campinas-SP, v. 66, n. 4, p. 527-533, 2007. 
CASTRO, P. R. C.; VIEIRA, E. L. Aplicações de reguladores vegetais na agricultura tropical. Guaíba-RS: Agropecuária, 2001. 132 p.

CASTRO, P. R. C.; KLYGE, R. A.; SESTARI, I. Manual de fisiologia vegetal: Fisiologia de cultivos. Piracicaba-SP: Editora Agronômica Ceres, 2008. 864p.

CECCON, G.; SILVA, JUSLEI, F.; NETO-NETO, A. L.; MAKINO, P. A.; SANTOS, A. Produtividade de milho safrinha em espaçamento reduzido com populações de milho e de Brachiaria ruziziensis. Revista Brasileira de Milho e Sorgo, Sete Lagoas-MG, v. 13, n.3, p. 326-335, 2014.

COBUCCI, T.; WRUCK, F. J.; KLUTHCOUSKI, J.; MUNIZ, L. C. MARTHA JUNIOR, G. B.; CARNEVALLI, R. A.; TEIXEIRA, S. R.; MACHADO, A. A.; TEIXEIRA NETO, M. L. Opções de Integração Lavoura-Pecuária e alguns de seus aspectos econômicos. Informe Agropecuário, Belo Horizonte-MG, v. 28, n. 240, p. 64-79, 2007.

CORTEZ, J. W.; FURLANI, C. E.A.; SILVA, R. P. Sistemas de adubação e consórcio de culturas intercalares e seus efeitos nas variáveis de colheita da cultura do milho. Engenharia Agrícola, Jaboticabal-SP, v. 29, n. 2, p. 277-287, 2009.

COSTA, A. S. V.; SILVA, M. B. Sistemas de consórcio milho-feijão para a região do Vale do Rio Doce, Minas Gerais. Ciência e Agrotecnologia, Lavras-MG, v. 32, n. 2, p. $663-$ $667,2008$.

CONAB: COMPANHIA NACIONAL DE ABASTECIMENTO. Brasil. Indicadores Agropecuários. Brasília-DF: Conab, Ano XXV, n. 9, 2016, 110 p. Disponível em: www.conab.gov.br. Acesso em: 20 out. 2016.

DEMINICIS, B. B. Leguminosas forrageiras tropicais: características importantes, recursos genéticos e causas dos insucessos de pastagens consorciadas. Viçosa-MG: Aprenda Fácil, 2009. 167 p.

DIAS-FILHO, M. B. Degradação de pastagens: processos, causas e estratégias de recuperação. 4. ed. Belém-PA: Edição do autor, 2011. $190 \mathrm{p}$.

EMBRAPA: EMPRESA BRASILEIRA DE PESQUISA AGROPECUÁRIA. Centro Nacional de Pesquisa de Solos. Sistema brasileiro de classificação de solos. 2 . ed. Rio de Janeiro-RJ: Embrapa Solos, 2006a. 306 p.

EMBRAPA: EMPRESA BRASILEIRA DE PESQUISA AGROPECUÁRIA. Centro Nacional de Pesquisa de Milho e Sorgo. Cultivo do milho. 2. ed. Sete Lagoas-MG: Embrapa Milho e Sorgo, 2010. 10 p.

FREITAS, R. J.; NASCENTE, A. S.; SANTOS, F. L. S. População de plantas de milho consorciado com Urochloa ruziziensis. Pesquisa Agropecuária Tropical, Goiânia-GO, v. 43, n. 1, p. 79-87, 2013.

HEINRICHS, R.; VITTI, G. C.; MOREIRA, A.; FIGUEIREDO, P. A.; FANCELLI, A. L.; CORAZZA, E. J. Características químicas de solo e rendimento de fitomassa de adubos verdes e de grãos de milho, decorrente do cultivo consorciado. Revista Brasileira de Ciência do Solo, Campinas-SP, v. 29, n. 1, p. 71-79, 2005.
IBGE: INSTITUTO BRASILEIRO DE GEOGRAFIA E ESTATÍSTICA. Censo agropecuário 1920/2006. Rio de Janeiro: IBGE, 2007. Disponível em: < http://seriesestatisticas.ibge. gov.br/>. Acesso em: 23 jul. 2016.

LEONEL, F. P.; PEREIRA, J. C.; COSTA, M. G.; MARCO JUNIOR, P.; SILVA, C. J.; LARA, L. A. Consórcio capimbraquiária e milho: comportamento produtivo das culturas e características nutricionais e qualitativas das silagens. Revista Brasileira de Zootecnia, Viçosa-MG, v. 38, n. 1, p. 166-176, 2009.

MAIA, P. B.; REZENDE, I. S.; TSUMURA, F.H. Desempenho de híbridos de milho e da forrageira Brachiaria brizantha em cultivo consorciado. Revista Verde de Agroecologia e Desenvolvimento Sustentável, Pombal-PB, v. 10, n. 1, p. $81-87,2015$.

MARCHÃO, R. L.; BRASIL, E. M.; DUARTE, J. B.; GUIMARÃES, C. M.; GOMES, J. A. Densidade de plantas e características agronômicas de híbridos de milho sob espaçamento reduzido entre linhas. Pesquisa Agropecuária Tropical, Goiânia-GO, v. 35, n. 2, p. 93-101, 2005.

MOREIRA, V. F.; PEREIRA, A. J.; GUERRA, J. G. M.; GUEDES, R. E.; COSTA, J. R. Produção de biomassa de guandu em função de diferentes densidades e espaçamentos entre sulcos de plantio. Seropédica-RJ: Embrapa Agrobiologia, 2003. 5 p. (Comunicado Técnico, 57).

NERES, M. A.; CASTAGNARA, D. D.; SILVA, F. B.; OLIVEIRA, P. S. R.; MESQUITA, E. E. BERNARDI, T. C.; GUARIANTI, A. J.; VOGT, A. S. L. Características produtivas, estruturais e bromatológicas dos capins Tifton 85 e Piatã e do feijão-guandu cv. Super N, em cultivo singular ou em associação. Ciência Rural, Santa Maria-RS, v. 42, n. 5, p. 862-869, 2012.

OLIVEIRA, P. P. A.; CORSI, M. Recuperação de pastagens degradadas para sistemas intensivos de produção de bovinos. São Carlos-SP: Embrapa Pecuária Sudeste, 2005. 23 p. (Circular Técnica, 38)

OLIVEIRA, P.; KLUTHCOUSKI, K.; FAVARIN, J. L.; SANTOS, D. C. Sistema Santa Brígida - Tecnologia Embrapa: Consorciação de milho com leguminosas. Santo Antônio de Goiás-GO: Embrapa Arroz e Feijão, 2010. 16p.

PIRES, A. J. V.; CARVALHO, G. G. P.; GARCIA, R.; CARVALHO JUNIOR, J.N.; RIBEIRO, L. S.O; CHAGAS, D. M. T. Fracionamento de carboidratos e proteínas de silagens de capim-elefante com casca de café, farelo de cacau ou farelo de mandioca. Revista Brasileira de Zootecnia, Viçosa-MG, v. 38, n. 3, p. 422-427, 2009.

SANTOS, M.V.; FERREIRA, F.A.; FREITAS, F.C.L.; TUFFI SANTOS, L.D.; FONSECA, D.M. Controle de Brachiaria brizantha com uso do glyphosate após o estabelecimento de Tifton 85 (Cynodon spp.). Planta Daninha, Viçosa-MG, v.24, n. 4, p. 813-819, 2006.

SIMPSON, R. L.; LECK, M. A. PARKER, V. T. Seed banks: General concepts and methodological issues. In: LECK, M. A.; PARKER, V. P.; SIMPSON, R. L. (Ed) Ecology of soil seed banks. New York: Academic Press, 1989, p. 69-86. 
SUZUKI, L. E. A. S.; ALVES, M. C. Fitomassa de plantas de cobertura em diferentes sucessões de culturas e sistemas de cultivo. Bragantia, Campinas-SP, v. 65, n. 1, p. 121-127, 2006.

VILELA, L.; MARTHA JUNIOR, G. B.; MACEDO, M. C. M.; MARCHÃO, R. L.; GUIMARÃES JÚNIOR, R.; KARINA PULROLNIK, K.; MACIEL, G. A. Sistemas de integração lavoura- -pecuária na região do Cerrado. Pesquisa Agropecuária Brasileira, Brasília-DF, v. 46, n. 10, p. 1.1271.138, 2011.
QUADROS, D. G.; ANDRADE, A. P.; OLIVEIRA, G. C.; OLIVEIRA, E. P.; MOSCON, E. S. Componentes da produção e qualidade de sementes dos cultivares marandu e xaraés de Brachiaria brizantha (Hochst. ex A. Rich.) Stapf colhidas por varredura manual ou mecanizada. Semina: Ciências Agrárias, Londrina-PR, v. 33, n. 5, p. 2019-2028, 2012. 